\title{
Primary care nurses' awareness of and willingness to perform children's oral health care
}

\author{
Sepideh Rabiei ${ }^{1,2+}$, Simin Z Mohebbi ${ }^{1,3+}$, Reza Yazdani ${ }^{1,3+}$ and Jorma I Virtanen ${ }^{2,4^{*}}$
}

\begin{abstract}
Background: The majority of young children receive no early dental examination while attending primary health care for routine check-ups. Our aim was to study primary care nurses' knowledge of oral health care $(\mathrm{OHC})$ and their attitudes toward delivering $\mathrm{OHC}$, as well as to assess their willingness to obtain $\mathrm{OHC}$ information.

Methods: We conducted a cross-sectional survey of all primary-care nurses working in the public health centres of Tehran city. An anonymous self-administered questionnaire queried their knowledge in paediatric-, general and medicine-related areas of dentistry, providing knowledge scores for three domains. The nurses' attitudes toward $\mathrm{OHC}$ and their willingness to obtain $\mathrm{OHC}$ information underwent evaluation with statements utilizing a five-point Likert scale. Altogether 680 nurses took part in the survey. The Chi-square test, $t$-test, one-way ANOVA and logistic regression model served for statistical analyses.
\end{abstract}

Result: The mean score for the paediatric dentistry domain (3.6, SD: 1.5) was lower than for the medical (4.4, SD: 2.3) and dental domains (5.8, SD: 1.5). Obtaining higher scores in the paediatric $(O R=1.2)$ and dental $(O R=1.3)$ domains, and a greater willingness to receive $\mathrm{OHC}$ information $(\mathrm{OR}=5.3)$, were associated with a positive attitude toward $\mathrm{OHC}$. Nurses with a lower education $(O R=1.9)$ and better oral health behaviour $(O R=1.1)$ as well as those working in a non-affluent region $(\mathrm{OR}=1.6)$ had a more positive attitude toward $\mathrm{OHC}$.

Conclusion: Primary care nurses' low level of knowledge in $\mathrm{OHC}$ and their positive attitude and willingness to obtain more information point to the need for appropriate $\mathrm{OHC}$ training and encouragement for the nurses to promote oral health and prevent dental diseases.

Keywords: Attitude, Children, Knowledge, Nurses, Oral health, Primary care providers

\section{Background}

The most common chronic disease affecting children's health all over the world is dental caries, which continues to pose a serious problem, particularly in lowincome populations $[1,2]$. Since dental care delivered by dentists is expensive, the dental caries of poor children often go untreated which leads to lower quality of life for them than for children in higher-income families $[3,4]$. Moreover, the majority of young children in many countries receive no dental examinations before the age of three though they frequently visit primary health care

\footnotetext{
* Correspondence: jorma.virtanen@oulu.fi

${ }^{\dagger}$ Equal contributors

${ }^{2}$ Department of Community Dentistry, University of Oulu, P.O. Box 5281,

90014 Oulu, Finland

${ }^{4}$ Oral and Maxillofacial Department, Oulu University Hospital, P.O. Box 21, 90029 Oulu, Finland

Full list of author information is available at the end of the article
}

providers for routine check-ups [5,6]. These routine check-ups provide a context within to integrate oral health promotion into the practices of non-dental staff in public health centres $[7,8]$.

Sharing the responsibility for children's oral health care $(\mathrm{OHC})$ with primary health care creates opportunities for joint ventures in target populations, since the same population is at high risk for other health and social problems. It is therefore more efficient to integrate oral health advices into general health messages by taking advantage of an approach that takes into consideration common health determinants for preventive measures [9]. This common risk factor approach calls for multiprofessional collaboration $[10,11]$. Comprehensive approaches are certainly even more important and efficient in health care service systems with less developed public dental services. 
Primary health nurses are easily accessible, as are lowcost health workers, who are in frequent contact with waiting mothers and children. Integrating $\mathrm{OHC}$ into these staff duties is expected to generate cost-effective preventive and health-promoting activities [12]. For example, involving vaccination staff in public health centres to deliver oral health instructions to parents has proved successful in reducing caries in toddlers [13-15]. On the other hand, studies have shown that nurses receive limited training in $\mathrm{OHC}$, and their knowledge in this field is inadequate $[1,16]$. In addition, other studies have identified attitudinal barriers among health staff as a major challenge [17].

In this survey, we aimed to study the knowledge of and attitudes towards oral health care among primary care nurses in Tehran as well as to assess their willingness to obtain $\mathrm{OHC}$ information.

\section{Methods}

\section{Study design and target population}

We designed a cross-sectional survey by means of a selfadministered questionnaire which the Ethics Committee of the Tehran University of Medical Sciences approved. The target population comprised all nurses working in the public health centres of Tehran in April 2011. Tehran has seven District Health Centres (DHC), which supervise 15 to 30 public health centres with varying numbers of nurses in each unit [18].

The DHCs agreed to distribute the questionnaires to nurses with a gift pack of a tooth-brush and dental floss and collect them in one week. The survey was voluntary and the responses were anonymous. Of the 690 nurses, 680 (97\% females) returned completed questionnaires (response rate: $99 \%$ ).

\section{Variables of the questionnaire and pilot study}

We developed the study questionnaire based on previously validated surveys of nurses' knowledge of, willingness to adopt and attitude toward $\mathrm{OHC}$ [18-21]. The content validity of the questionnaire was evaluated by experts in dental public health. Then we conducted a pilot study (test/re-test at a two-week interval) among physicians and nurses ( $\mathrm{n}=$ 30) working in the public health centers of Qazvin, a city near Tehran. We revised the questionnaire according to the pilot study. The questionnaire comprised statements on knowledge, attitude, and willingness for $\mathrm{OHC}$ education and background factors.

\section{Knowledge questions}

The questionnaire was a slightly modified version of one used in a similar study performed among primary care physicians and consisted of three domains: a) paediatric dental knowledge, b) general dental knowledge and c) dentistry-related medical knowledge [18].
Each domain included nine questions. In the paediatric domain, the questionnaire enquired about the time of tooth eruption; the time to start brushing and cleaning teeth and using fluoride; the transmission of bacteria; carcinogenicity of breast milk compared to the formula; and the effects of dummy sucking. The dental domain included questions on the first signs of tooth decay and its aetiology, the effects of fluoride and xylitol, the best time to refer a pregnant woman for a dental procedure, and the main cause of periodontal diseases. The medical domain consisted of questions on the relationship between systemic and periodontal diseases, and how drugs increase the risk for dental caries [18].

\section{Attitude questions}

We measured nurses' attitudes on a five-point Likert scale using eight statements describing the nurses' opinions about $\mathrm{OHC}$ and their role in preventing oral diseases: "Dental caries and periodontitis can be stopped", "Nurses should examine the oral cavity ", "Routine dental visits are effective in preventing dental diseases", "Nurses may play an important role in preventing oral diseases", "Oral health care delivered by nurses is inefficient", "Having oral health problems can lead to general health problems", "I would like to implement preventive oral health activities" and "Prevention is more important than other activities". Their responses ranged from "strongly agree" to "strongly disagree”, including "don't know”.

\section{Willingness question}

We also measured nurses' willingness to obtain more training in oral health with a statement asking "How much are you willing to obtain more information about oral health?" and five Likert response alternatives: 1) very much, 2) much, 3) little, 4) very little, 5) not at all.

\section{Backgrounds}

Socio-demographics included age, gender, educational degree, work experience (in years), and the socio-economic status of the region in which the public health centres are located (affluent/non-affluent). We also assessed the nurses' oral health behaviour $(\mathrm{OHB})$ with five questions about their "frequency of tooth brushing" (Irregularly or never, Once a week, A few (2-3) times a week, Once a day, More than once a day), "using fluoride tooth-paste" (Always or almost always, Rather often, Seldom, Never), "flossing" (Not at all, Occasionally, A few (2-3) times a week, Once a day, More than once a day), "eating sugar-containing snacks between meals" (About three times a day or more, About twice a day, About once a day, Occasionally (not every day), Rarely) and "the time of your last dental check-up" (Within six months, Six months to one year ago, One to two years ago, Two to five years ago, More than five years ago, Never, Do not remember). 


\section{Data analyses}

We dichotomised the answers to the knowledge questions to " 1 " for correct answers and "0" for false and "don't know" answers. Thereafter, we calculated a total score for the knowledge category (range: 0-23) as well as its three domains [paediatric dental (range: 0-9), general dental (range: 0-9) and medical (range: 0-9)]. For the attitude questions, we scored response alternatives from 0 to 4 . We then calculated a total score for each person (range: 0-32).

We coded the responses to the OHB questions such that higher scores represented more desirable habits $(1-7)$, and then calculated a sum variable for OHB. For further analysis, we divided the sum variable of paediatric knowledge, attitude, and $\mathrm{OHB}$ into three categories, based on the 33rd percentile for the responses, as low, medium and high scores.

\section{Statistical analysis}

Evaluation of the statistical significance of the differences between the subgroups included the independent samples $t$-test and one-way ANOVA for the comparison of mean values, and the Chi-square test for frequencies. We used analysis of variance with repeated measurements and the paired samples $t$-test to evaluate statistical significances between the mean scores.
A logistic regression model served in the multivariate assessment of factors related to a high score in attitude compared to those related to a low score. We then determined the corresponding odds ratios (OR) and their 95\% confidence intervals (95\% CI). We used the Hosmer and Lemeshow test to assess goodness of fit $(\mathrm{p}=0.146)$.

\section{Results}

\section{Backgrounds}

The participants varied in age from 22 to 56 years (mean: 37 years, SD: 8), and a majority of them were women (97\%). Table 1 shows the distribution of those primary care nurses working in the public health centres according to their background characteristics. Among the nurses, 66\% had higher educational degrees (BS and MS), $27 \%$ had two-years of university education, and $7 \%$ had either a diploma or less than a diploma. In the nonaffluent area, more nurses held lower degrees than did nurses in the affluent area. The nurses' OHB score ranged from 10 to 26 (mean $=19.71, \mathrm{SD}: 2.55)$.

\section{Knowledge of oral health}

The nurses' knowledge of oral health scores appear in Table 2 according to their backgrounds. The mean score for the paediatric dentistry domain (3.6, SD: 1.5) was lower than that for the medical (4.4, SD: 2.3) and dental

Table 1 Distribution of nurses $(n=680)$ working in public health centres according to background characteristics in Tehran, Iran

\begin{tabular}{|c|c|c|c|c|c|}
\hline & & \multicolumn{4}{|c|}{ DHCs Area } \\
\hline & & Affluent (\%) & Non-affluent (\%) & Total (\%) & $p$-value \\
\hline \multicolumn{6}{|c|}{ Age } \\
\hline & 22-36 year-olds & $125(40)$ & $171(53)$ & $296(46)$ & \multirow[t]{3}{*}{0.001} \\
\hline & 37-56 year-olds & $190(60)$ & $151(47)$ & $341(54)$ & \\
\hline & Total & $315(100)$ & $322(100)$ & $637(100)$ & \\
\hline \multicolumn{6}{|c|}{ Gender } \\
\hline & Female & $324(99)$ & $324(96)$ & $648(97)$ & \multirow[t]{3}{*}{0.005} \\
\hline & Male & $3(1)$ & $15(4)$ & $18(3)$ & \\
\hline & Total & $327(100)$ & $339(100)$ & $666(100)$ & \\
\hline \multicolumn{6}{|c|}{ Educational degree } \\
\hline & Diploma and lower & $7(2)$ & $38(12)$ & $45(7)$ & \multirow[t]{4}{*}{0.000} \\
\hline & 2 years study & $95(30)$ & $74(24)$ & $169(27)$ & \\
\hline & $\mathrm{BS}$ and $\mathrm{MS}$ & $215(68)$ & $201(64)$ & $416(66)$ & \\
\hline & Total & $317(100)$ & $313(100)$ & $630(100)$ & \\
\hline \multicolumn{6}{|c|}{$\mathrm{OHB}$} \\
\hline & Low & $75(23)$ & $133(40)$ & 208(32) & \multirow[t]{4}{*}{0.000} \\
\hline & Medium & $150(47)$ & 139(42) & $289(44)$ & \\
\hline & High & $95(30)$ & $61(18)$ & $156(24)$ & \\
\hline & Total & $320(100)$ & $333(100)$ & $653(100)$ & \\
\hline
\end{tabular}


Table 2 The nurses' $(n=680$ ) knowledge scores (mean, SD) in three domains according to their background characteristics in Tehran, Iran

\begin{tabular}{|c|c|c|c|c|}
\hline & $\begin{array}{c}\text { Paediatric knowledge } \\
\text { Mean (SD) }\end{array}$ & $\begin{array}{c}\text { Dental knowledge } \\
\text { Mean (SD) }\end{array}$ & $\begin{array}{c}\text { Medical knowledge } \\
\text { Mean (SD) }\end{array}$ & $\begin{array}{c}\text { Total knowledge } \\
\text { Mean (SD) }\end{array}$ \\
\hline \multicolumn{5}{|l|}{ Age } \\
\hline 22-36-year-olds & $3.6(1.5)$ & $5.8(1.5)$ & $4.3(2.2)$ & $13.8(3.6)$ \\
\hline 37-56-year-olds & $3.5(1.4)$ & $5.8(1.3)$ & $4.4(2.3)$ & $13.8(3.4)$ \\
\hline$p$-value & .448 & .973 & .565 & .973 \\
\hline \multicolumn{5}{|l|}{ Gender } \\
\hline Female & $3.6(1.5)$ & $5.8(1.4)$ & $4.4(2.3)$ & $13.7(3.5)$ \\
\hline Male & $3.9(1.8)$ & $5.9(1.5)$ & $3.8(2.2)$ & $13.7(3.7)$ \\
\hline$p$-value & .387 & .597 & .291 & .993 \\
\hline \multicolumn{5}{|l|}{ Working Area } \\
\hline Affluent & $3.6(1.5)$ & $5.8(1.3)$ & $4.6(2.3)$ & $14.0(3.6)$ \\
\hline Non-Affluent & $3.6(1.5)$ & $5.7(1.6)$ & $4.2(2.2)$ & $13.5(3.5)$ \\
\hline p-value & .556 & .186 & .018 & .067 \\
\hline \multicolumn{5}{|l|}{ Work experience } \\
\hline $0-5$ years & $3.7(1.5)$ & $5.8(1.6)$ & $4.5(2.2)$ & $13.9(3.9)$ \\
\hline $6-14$ years & $3.4(1.5)$ & $5.7(1.5)$ & $4.3(2.4)$ & $13.4(3.5)$ \\
\hline $15-30$ years & $3.7(1.4)$ & $5.9(1.2)$ & $4.5(2.3)$ & $14.1(3.2)$ \\
\hline$p$-value* & .116 & .246 & .656 & .119 \\
\hline \multicolumn{5}{|l|}{ Educational degree } \\
\hline Diploma and lower & $4.4(1.8)$ & $5.8(1.3)$ & $3.4(2.4)$ & $13.6(3.4)$ \\
\hline 2 years study & $3.6(1.4)$ & $5.8(1.4)$ & $4.5(2.4)$ & $13.9(3.4)$ \\
\hline $\mathrm{BS}$ and $\mathrm{MS}$ & $3.4(1.4)$ & $5.7(1.5)$ & $4.5(2.2)$ & $13.6(3.6)$ \\
\hline$p$-value* & .000 & .747 & .012 & .664 \\
\hline \multicolumn{5}{|l|}{$\mathrm{OHB}$} \\
\hline Low & $3.7(1.6)$ & $5.6(1.5)$ & $4.0(2.3)$ & $13.4(3.4)$ \\
\hline Medium & $3.6(1.5)$ & $5.9(1.4)$ & $4.6(2.10$ & $14.0(3.4)$ \\
\hline High & 3.5 (1.4) & $5.8(1.4)$ & $4.6(2.4)$ & 13.8 (3.8) \\
\hline P-value* & .324 & .215 & .013 & .140 \\
\hline Total $£$ & $3.6(1.5)$ & $5.8(1.5)$ & $4.4(2.3)$ & $13.7(3.5)$ \\
\hline
\end{tabular}

OHB (Oral Health Behaviour): Low $=10-18$, Medium $=19-21$, High $=22-26$.

Statistical analyses by $T$-test, ${ }^{*}$ One-way ANOVA and $£$ Repeated measurements.

(5.8, SD: 1.5$)$ domains $(\mathrm{p}<0.001)$. In the paediatric dentistry domain, the smallest number of correct answers was for dummy sucking (13\%). About one-fourth of the nurses knew the correct time of tooth eruption (24\%), the time to use fluoride toothpaste (26\%), about the transmission of bacteria from mother to child (27\%), while $80 \%$ were knowledgeable about the lesser carcinogenicity of breast milk compared to the formula. In the dental domain, the lowest percentage of correct answer was for the first sign of dental caries (48\%) and the highest for the aetiology of dental caries (92\%). In the medical domain, the percentage of correct answers regarding the relationship between periodontal and systemic diseases ranged between $60 \%$ and $79 \%$, while the percentages for the effects of drugs on dental caries were $20 \%$ to $40 \%$.

The nurses working in the affluent area had higher scores in total knowledge and in the medical domain than did their colleagues working in the non-affluent area. The knowledge of medicine score was the lowest among nurses with low OHB scores $(\mathrm{p}<0.05)$.

\section{Attitude toward $\mathrm{OHC}$}

The mean score of the nurses' attitudes toward $\mathrm{OHC}$ was 22 (SD: 5.5). Figure 1 shows that almost all nurses had generally positive attitudes toward preventive $\mathrm{OHC}$. In their opinion, routine dental visits are effective (94\%), and they were aware of the relationship between dental 


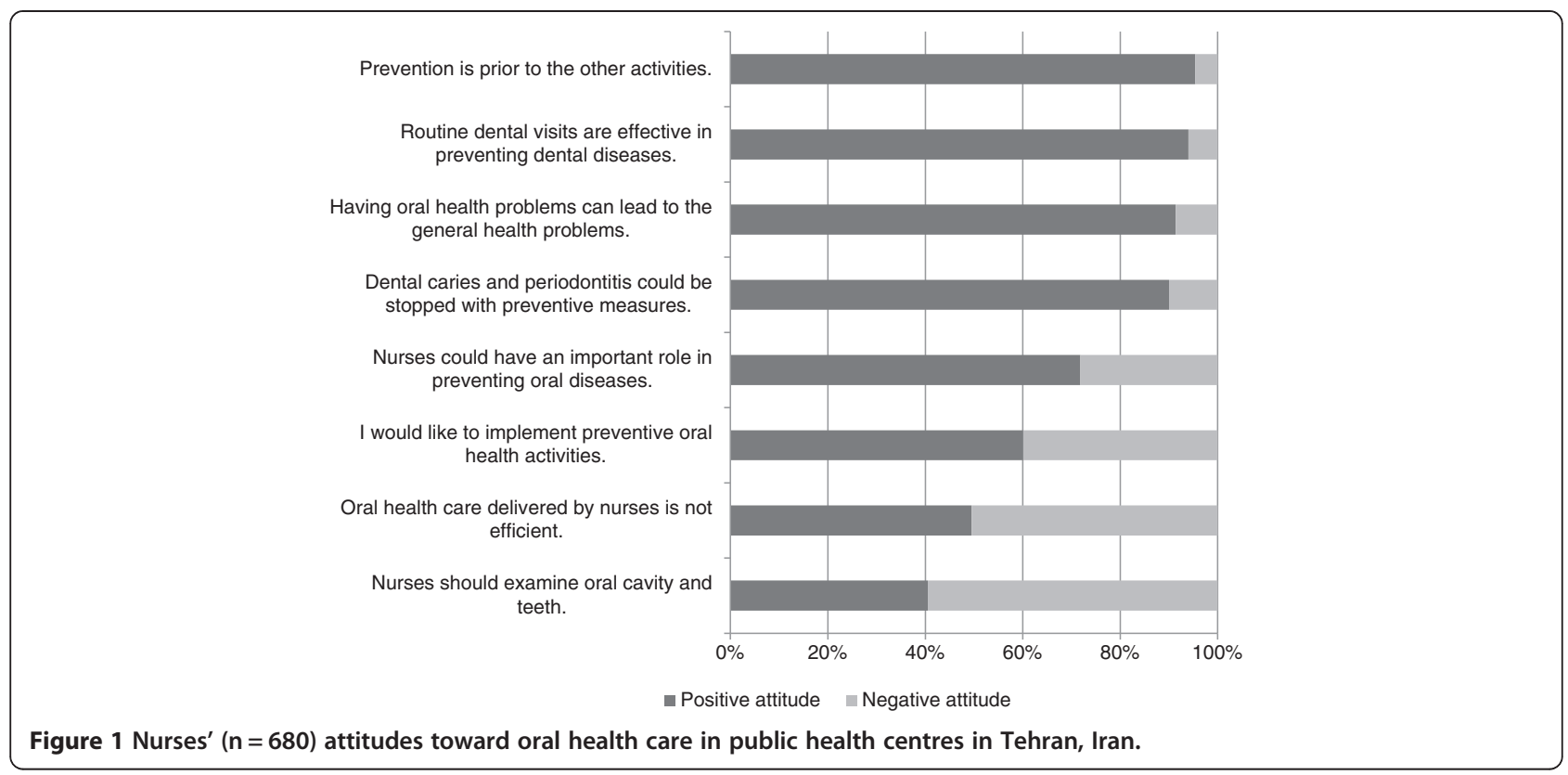

and general health (91\%). Most (72\%) of them believed that they could play an important role in preventing oral diseases, while $60 \%$ were interested in implementing preventive activities for their patients. Half $(49 \%)$ of the nurses believed that $\mathrm{OHC}$ delivered by nurses is efficient, and $40 \%$ thought that they should examine the oral cavity and teeth during routine patient visits. Table 3 shows that nurses with higher paediatric knowledge scores held more positive attitudes toward preventive $\mathrm{OHC}$ than did those with lower paediatric knowledge scores.

\section{Willingness to obtain $\mathrm{OHC}$ information}

Most nurses (69\%) were willing to learn more about $\mathrm{OHC}$. Younger nurses, nurses working in the non-affluent area, and those with less work experience were more willing in this regard than were their older colleagues, those who were working in the affluent area and those who had more experience $(\mathrm{p}=0.001)$.

\section{Multivariate analysis}

After controlling for other background characteristics, the logistic regression model revealed that higher scores in the paediatric $(\mathrm{OR}=1.2,95 \% \mathrm{CI}: 1.0-1.4)$ and dental $(\mathrm{OR}=1.3,95 \% \mathrm{CI}: 1.1-1.6)$ domains and a greater willingness to learn more about $\mathrm{OHC}(\mathrm{OR}=5.3,95 \% \mathrm{CI}$ : 3.2-8.8) were associated with a positive attitude toward $\mathrm{OHC}$ (Table 4).

Nurses with a lower educational degree $(\mathrm{OR}=1.9,95 \%$ CI: $1.3-2.8)$, better $\mathrm{OHB}(\mathrm{OR}=1.1,95 \% \mathrm{CI}: 1.0-1.2)$, and those working in the non-affluent area $(\mathrm{OR}=1.6,95 \% \mathrm{CI}$ : 1.0-2.5) held a more positive attitude toward $\mathrm{OHC}$ than did those with a higher educational degree, a lower OHB score, and those working in the affluent area $(\mathrm{p}<0.05)$.

\section{Discussion}

Our study showed a great lack of knowledge of $\mathrm{OHC}$ among primary care nurses working in the public health centres of Tehran. The nurses, however, clearly acknowledged the importance of prevention and showed a great willingness as well as a positive attitude towards improving their skills in this field.

\section{OHC knowledge}

The present study revealed a low level of oral health knowledge among the nurses; because they correctly answered on average half of the questions related to oral health knowledge. Another study has reported similar findings among primary care personnel [18]. In a study of nurse practitioners' knowledge, opinions and practice behaviours regarding oral disease and its outcomes, Wooten et al. also reported that nurses have limited knowledge of oral health [16].

In many countries with developing health care systems, most young children are not included in regular dental recall systems by dentists until they reach the age of three to six years; they do, however, see primary care providers - including nurses - up to ten times for health screenings and vaccinations before their first birthday [19]. Consequently, this professional group can play a key role in the early prevention of oral diseases in children. Although the WHO recommends integrating oral health promotion with general health promotion and provides technical and policy support for countries to achieve this goal [22], primary care providers receive 
Table 3 Primary care nurses' $(n=680)$ attitudes toward dental health care and their paediatric knowledge scores in Tehran, Iran

\begin{tabular}{|c|c|c|c|c|c|c|}
\hline & & \multicolumn{4}{|c|}{ Paediatric knowledge score } & \multirow[b]{2}{*}{$\mathrm{p}$-value } \\
\hline & & Low (\%) & Medium (\%) & High (\%) & Total (\%) & \\
\hline \multicolumn{7}{|l|}{ Attitude } \\
\hline & Low & 60 & 115 & 50 & 225 & .052 \\
\hline & & (35) & (34) & (30) & (33) & \\
\hline & Medium & 67 & 118 & 51 & 236 & \\
\hline & & (40) & (34) & (30) & (35) & \\
\hline & High & 48 & 109 & 68 & 219 & \\
\hline & & (23) & (32) & (40) & (32) & \\
\hline & Total & 169 & 342 & 169 & 680 & \\
\hline & & $(100)$ & $(100)$ & $(100)$ & $(100)$ & \\
\hline
\end{tabular}

Paediatric knowledge score: Low $=0-2$, Medium $=3-4$, High $=5-8$.

Attitude score: Low =0-19, Medium $=20-24$, High $=25-32$.

Statistical analyses by Chi square test.

limited training in this field $[1,23,24]$, and particularly in the field of paediatric dentistry, as our study revealed. This finding is also consistent with the low levels of knowledge of paediatric $\mathrm{OHC}$ among primary care physicians in the same public health care setting in Tehran [18].

As the WHO emphasised, offering oral health care in developing countries within the context of primary health care programmes is important [22]. In many health care systems, primary care nurses may be the only trustworthy source of oral health preventive information from birth based on their early relationships with young children and their parents. If given appropriate training in this field, nurses can consult with parents on, for example, feeding practices, oral home care (brushing/flossing), and the use of fluorides early on in the child's life. Moreover, they could also help to diagnose caries in their early stages by referring children to dental clinics for further examination and preventive procedures or possible treatment. Studies have shown that these auxiliary workers have a considerable impact on preventive activities and are a potential target for educational interventions [25-27].

Although the nurses' knowledge of $\mathrm{OHC}$ was relatively low, priming their knowledge of oral health issues and supporting their practices would benefit the promotion of oral health. Since OHC training in the basic educational curriculum of public health nurses may often be limited, there is a need to broaden their awareness and collaboration in $\mathrm{OHC}$ through organised training such as continuous education. Studies have shown that continuous and periodic education offers both short-term and long-term knowledge gains and could well be planned to target primary care nurses working in public health centres [28]. Several studies (e.g. Kuronen et al. 2011) have shown that such interventions proved successful among these professionals [25].

Table 4 Factors associated with nurses' $(n=680)$ attitudes (high/low) toward oral health care controlling for background characteristics as shown by a logistic regression model

\begin{tabular}{|c|c|c|c|c|c|c|}
\hline & \multirow[t]{2}{*}{ B } & \multirow[t]{2}{*}{ S.E. } & \multirow[t]{2}{*}{ Sig. } & \multirow[t]{2}{*}{ OR } & \multicolumn{2}{|c|}{ 95\% C.I. for OR } \\
\hline & & & & & Lower & Upper \\
\hline Paediatric score & 0.19 & 0.08 & .020 & 1.21 & 1.03 & 1.43 \\
\hline Dental score & 0.28 & 0.09 & .001 & 1.33 & 1.12 & 1.57 \\
\hline Medical score & 0.07 & 0.05 & .170 & 1.08 & 0.97 & 1.19 \\
\hline $\mathrm{OHB}$ & 0.11 & 0.05 & .020 & 1.12 & 1.02 & 1.23 \\
\hline Working area & 0.47 & 0.24 & .049 & 1.59 & 1.00 & 2.53 \\
\hline Willingness to Receive information & 1.67 & 0.26 & .000 & 5.31 & 3.21 & 8.78 \\
\hline Educational degree & 0.64 & 0.19 & .001 & 1.89 & 1.29 & 2.77 \\
\hline
\end{tabular}

All variables were used in their continuous form except for degree, working area, and willingness to receive information.

Educational degree: 1 = BS and MS, 2 = two years university studies, $3=$ diploma and lower.

Working area: 1 = affluent area, $2=$ non-affluent area.

Willingness to receive information: 0 : No, 1: Yes.

Goodness of fit with Hosmer and Lemeshow test, $\mathrm{P}$ - value $=0.146$. 


\section{Attitudes among nurses}

The nurses generally held positive attitudes toward $\mathrm{OHC}$ and admitted that they should be more knowledgeable in this field. Of the nurses, more than $90 \%$ identified the relationship between dental and general health and believed that routine dental visits are effective in preventing oral diseases. However, fewer than half of them were interested in incorporating $\mathrm{OHC}$ into their routine patient visits, perhaps because of their hectic daily workload or, as Fulmer et al. (2012) reported, because they may think that "oral examination is not in their scope of practice" [29]. In contrast, another study reported that nurses were interested in implementing screening for their patients [16]. Despite most nurses' belief in their essential role in preventing oral diseases, only half of them believed that their $\mathrm{OHC}$ would be effective. This finding may be related to the nurses' awareness of their low level of knowledge in the field. Nurses with higher knowledge scores, especially in the paediatric and dental domains, and those more willing to learn more about oral health showed more positive attitudes. Furthermore, in our study, nurses with higher attitude scores were more willing to receive additional training in $\mathrm{OHC}$, which would likely lead to improvements in their knowledge in the area. Our findings emphasise the necessity of appropriate training and encouragement for nurses working in primary care, a process which has proved effective in providing oral health promotion and disease prevention activities [19].

Surprisingly, nurses with a lower educational degree held more positive attitudes toward $\mathrm{OHC}$, possibly showing that those with more education might focus their interest on more specific duties such as visiting waiting mothers for their routine check-ups, advising them about their self-care and diet, and prescribing drugs (if needed) rather than consulting about their own or their child's $\mathrm{OHC}$.

\section{Willingness to obtain oral health information}

Nurses in the present survey were interested in obtaining more training in $\mathrm{OHC}$, which is in line with the results of a previous study in which nurses agreed on the need for more information in this topic [16] as well as on the willingness of Iranian primary health care personnel to receive more $\mathrm{OHC}$ training [18]. The finding that younger nurses and those who had less work experience were more willing to expand their knowledge may be due to the workload of their experienced colleagues and their lack of time [30].

\section{Socio-economic status}

Our study included DHCs from both affluent and nonaffluent parts of the city of Tehran. In the affluent parts of the city, access to private dental care practice is extensive, and the people there can more easily afford these services than can those in the non-affluent regions. The nurses' level of knowledge proved to be lower in the non-affluent areas, where children may have a greater need for dental care [31]. Nevertheless, their positive attitude and notable insight into how to deliver $\mathrm{OHC}$ through their routine patient care is promising. In addition, both nurses and physicians in the non-affluent area were more willing to receive training in $\mathrm{OHC}$ [18]. These findings may be related to their awareness of the formidable challenges poor access to care pose to better oral health $[19,32]$. The nurses are in frequent contact with children from disadvantaged families who may suffer from various dental diseases. Untreated dental diseases can have a substantial impact on children's well-being in low-income populations [33,34]. Our findings call for $\mathrm{OHC}$ training for primary care nurses especially among non-privileged populations.

\section{Primary care in Tehran}

The organised public health system for delivering primary health care in Iran was established in the 1970s, and $\mathrm{OHC}$ was integrated into the nationwide primary health care network in 1997. Several public health care centres with different health care units, such as medical, family health, maternity and vaccination units, with a number of primary care nurses, work under the supervision of DHCs. About $60 \%$ of these centres have an $\mathrm{OHC}$ unit with a dentist who is in charge of basic $\mathrm{OHC}$ services, such as restorations, scaling and extractions, mainly for 6- to 12-year-olds through a school-based national programme, as well as for pregnant and nursing mothers [5]. Because of the extremely young population of the country and the high prevalence of dental caries in children under the age of six, a public health approach which takes this young population into account is essential and could best be achieved by incorporating the great potential of non-dental staff, including nurses in primary health care $[17,18]$.

\section{Integration}

Previous studies have shown that primary care medical providers, and nurses in particular, can play an important role in helping individuals gain access to $\mathrm{OHC}$ and in introducing successful preventive measures, particularly for children at the highest risk for early childhood caries in underserved areas [32,33,35]. The WHO Global Oral Health programme emphasises that oral health is integral and essential to general health, and that any attempt to improve oral health should be integrated into other health-promoting strategies and actions [36]. Dental and paediatric associations have also underscored the importance of integrating oral health into general health for sharing the responsibility of $\mathrm{OHC}$ with primary care medical practitioners [8,34]. 


\section{Strengths and limitations of the study}

The study included all nurses working in the public health centres of Tehran, and the high response rate speaks for the representativeness of the present study and increases its value. Our cross-sectional design permits investigation of potential associations between one's attitude and level of knowledge; causality clearance, however, would require a longitudinal design. Surveys with a self-administered questionnaire may also have some typical shortcomings, such over- and under reporting due to social acceptance, a phenomenon that the anonymous character of this study may have minimized.

\section{Conclusions}

Our study revealed a low level of knowledge in OHC among primary care nurses, who simultaneously exhibited a generally positive attitude and notable willingness to obtain more training in this field. These findings point to an essential need for appropriate training and encouragement in $\mathrm{OHC}$, especially among nurses working in developing health care systems, to promote oral health and to provide suitable conditions for the prevention of dental diseases.

\section{Abbreviations}

DHC: District Health Centre; OHC: Oral Health Care.

\section{Competing interest}

The authors declare that they have no competing interests.

\section{Authors' contributions}

The authors SR, SZM, RY, JIV have contributed equally to this work in making substantial contributions to conception and design, acquisition of data, and analysis and interpretation of data and being involved in drafting the manuscript or revising it critically for important intellectual content. All authors read and approved the final manuscript.

\section{Acknowledgments}

This work was supported by Tehran University of Medical Sciences \& Health Services [grant number 90-01-69-12912]. We are grateful to the nurses at the public health centres and medical education staff at the DHCs for their excellent collaboration

\section{Author details}

${ }^{1}$ Community Oral Health Department, Tehran University of Medical Sciences, P.O. Box 1439955991, Tehran, Iran. ²Department of Community Dentistry, University of Oulu, P.O. Box 5281, 90014 Oulu, Finland. ${ }^{3}$ Department of Oral Public Health, University of Helsinki, P.O. Box 41FI-00014 Helsinki, Finland. ${ }^{4}$ Oral and Maxillofacial Department, Oulu University Hospital, P.O. Box 21, 90029 Oulu, Finland.

Received: 9 September 2013 Accepted: 21 March 2014

Published: 26 March 2014

\section{References}

1. Lewis CW, Grossman DC, Domoto PK, Deyo RA: The role of the pediatrician in the oral health of children: a national survey. Pediatrics 2000, 106:e84

2. Hallas $D$, Shelley D: Role of pediatric nurse practitioners in oral health care. Acad Pediatr 2009, 9:462-466.

3. US Government Accountability Office: Oral health: dental disease is a chronic problem among low-income population. [http://www.gao.gov/ cgi-bin/getrpt?GAO/HEHS-00-72]
4. Spielman Al, Fulmer T, Eisenberg ES, Alfano MC: Dentistry, nursing and medicine: a comparison of core competencies. J Dent Educ 2005, 69:1257-1271

5. Samadzadeh $\mathrm{H}$, Hessari $\mathrm{H}$, Naghavi M: Oral Health Situation of Iranian Children, Tehran, Ministry of Health and Medical Education, Oral Health Bureau. Seow WK: Biological Mechanisms of Early Childhood; 1999.

6. Wendt LK, Carlsson E, Hallonsten AL, Birkhed D: Early dental caries risk assessment and prevention in pre-school children: evaluation of a new strategy for dental care in a field study. Acta Odontol Scand 2001 59:261-266

7. Raybound TP, Wrightson AS, Massey CS, Smith TA, Skelton J: Advanced general dentistry program directors' attitudes on physician involvement in pediatric oral health care. Spec Care Dentist 2009, 29:232-236.

8. Hale KJ, American Academy of Pedatrics section on Pediatric Dentistry: Oral health risk assessment timing and establishment of the dental home. Pediatrics 2003, 111:1113-1116.

9. Mouradian WE: The face of a child: children's oral health and dental education. J Dent Educ 2001, 65:821-831.

10. WHO (World Health Organization): Global Strategy for the Prevention and Control of non Communicable Diseases. Geneva: WHO; 2000.

11. Sheiham A, Watt RG: The common risk factor approach: a rational basis for promoting oral health. Community Dent Oral Epidemiol 2000, 28:399-406.

12. Jesmin S, Thind A, Sarma S: Does team-based primary health care improve patients' perception of outcomes? Evidence from the 2007-08 Canadian survey of experiences with primary health. Health Policy 2012, 105:71-83.

13. Mohebbi SZ, Virtanen Jl, Vahid-Golpayegani M, Vehkalahti MM: A cluster randomized trial of effectiveness of educational intervention in primary health care on early childhood caries. Caries Res 2009, 43:110-118.

14. Ekstrand KR, Kuzmina IN, Kuzmina E, Christiansen ME: Two and a half-year outcome of caries-preventive programs offered to groups of children in the Solntsevsky district of Moscow. Caries Res 2000, 34:8-19.

15. Feldens CA, Vitolo MR, Drachler Mde L: A randomized trial of the effectiveness of home visits in preventing early childhood caries. Community Dent Oral Epidemiol 2007, 35:215-223.

16. Wooten KT, Lee J, Jared H, Boggess K, Wilder RS: Nurse Practitioners' and certified nurse midwives' knowledge, opinions and practice behaviors regarding periodontal disease and adverse pregnancy outcomes. J Dent Hyg 2011, 85:122-131.

17. Mohebbi SZ: Early Childhood Caries and a Community Trial of its Prevention in Tehran, Iran. PhD thesis, University of Helsinki, Oral Public Health Department. 2008 [http:/ethesis.helsinkifi/julkaisut/laa/hamma/vk/mohebbi/

18. Rabiei S, Mohebbi SZ, Patja K, Virtanen Jl: Physicians' knowledge of and adherence to improving oral health. BMC Public Health 2012, 12:855.

19. dela Cruz GG, Rozier RG, Slade G: Dental screening and referral of young children by pediatric primary care providers. Pediatrics 2004, 114:642-652.

20. Di Giuseppe G, Nobile CG, Marinelli A, Angelillo IF: Knowledge, attitude and practices of Pediatricians regarding the prevention of oral diseases in Italy. BMC Public Health 2006, 6:176.

21. Prakash P, Lawrence HP, Harvey B, Maclsaac WJ, Limeback H, Leake JL: Early childhood caries and infant oral health: Pediatricians' knowledge, practices and training. Paediatr Child Health 2006, 11:151-157.

22. Peterson PE: Challenges to improvement of oral health in the $21 \mathrm{st}$ century-the approach of the WHO global oral health programme. Int Dent J 2004, 54:329-343.

23. Curtis JW Jr, Garrison RS Jr, Camp MG: Dentistry in medical education: result of a comprehensive survey. J Med Educ 1985, 60:16-20.

24. Midwifery curriculum. [http://fnm.tums.ac.ir/85516/sec_18/p_20.aspx? lang=fa]

25. Kuronen $\mathrm{R}$, Jallinoja P, Patja K: Use of and attitudes toward current care guidelines among primary and secondary care nurses in Finland. Clin Nurs Res 2011, 20:310-325

26. Amemori M, Virtanen J, Korhonen T, Kinnunen TH, Murtomaa H: Impact of educational intervention on implementation of tobacco counseling among oral health professionals: a cluster randomized community trial. Community Dent Oral Epidemiol 2013, 41:120-129.

27. Ford CR, Foley KT, Ritchie CS, Sheppard K, Sawyer P, Swanson M, Harada CN Brown $\mathrm{CJ}$ : Creation of an interprofessional clinical experience for healthcare professions trainees in a nursing home setting. Med Teach 2013, 35:544-548. 
28. Marinopoulos SS, Dorman T, Ratanawongsa N, Wilson LM, Ashar BH, Magaziner JL, Miller RG, Thomas PA, Prokopowicz GP, Qayyum R, Bass EB: Effectiveness of continuing medical education. Evid Rep Technol Assess 2007, 149:1-69.

29. Fulmer T, Cabrera P: The primary care visit: what else could be happening? Nurs Res Pract 2012, 2012:720506. doi:10.1155/2012/720506. Epub 2012 Jun 10.

30. Lewis CW, Cantrell DC, Domoto PK: Oral health in the pediatric practice setting: a survey of Washangton State pediatrics. J Public Health Dent 2004, 64:111-114.

31. Newacheck PW, Hughes DC, Hung YY, Wong S, Stoddard JJ: The unmet health needs of America's children. Pediatrics 2000, 105:989-997.

32. Nowak AJ, Casamassimo PS: Using anticipatory guidance to provide early dental intervention. J Am Dent Assoc 1995, 126:1156-1163.

33. Wysen KH, Hennessy PM, Lieberman MI, Garland TE, Johnson SM: Kids Get Care: integrating preventive dental and medical care using a public health case management model. J Dent Educ 2004, 5:522-530.

34. Haden NK, Catalanotto FA, Alexander CJ, Bailit H, Battrell A, Broussard J Jr, Buchanan J, Douglass CW, Fox CE 3rd, Glassman P, Lugo Rl, George M, Meyerowitz C, Scott ER 2nd, Yaple N, Bresch J, Gutman-Betts Z, Luke GG, Moss M, Sinkford JC, Weaver RG, Valachovic RW: Improving the oral health status of all Americans: roles and responsibilities of academic dental institutions: the report of the ADEA President's Commission. J Dent Educ 2003, 67:563-583.

35. Nagarajappa R, Kakatkar G, Sharda AJ, Asawa K, Ramesh G, Sandesh N: Infant oral health: Knowledge, attitude and practices of parents in Udaipur. India. Dent Res J (Isfahan) 2013, 10:659-665.

36. Petersen PE: Global policy improvement of oral health in the 21st century - implications to oral health research of world Health Assembly 2007, World Health Organization. Community Dent Oral Epidemiol 2009, $37: 1-8$.

doi:10.1186/1472-6831-14-26

Cite this article as: Rabiei et al:: Primary care nurses' awareness of and willingness to perform children's oral health care. BMC Oral Health 2014 14:26

\section{Submit your next manuscript to BioMed Central and take full advantage of:}

- Convenient online submission

- Thorough peer review

- No space constraints or color figure charges

- Immediate publication on acceptance

- Inclusion in PubMed, CAS, Scopus and Google Scholar

- Research which is freely available for redistribution 